\title{
Aspirations and ambiguities - The need for focused IAG for school pupils considering progression to higher education (HE).
}

\section{Dr David W. Thompson. University of Wolverhampton, Institute of Education.}

\author{
d.w.thompson@wlv.ac.uk
}

\begin{abstract}
The provision of Information, Advice and Guidance (IAG) for school pupils considering their next move after compulsory schooling is of great importance to them and their families. This study focussed on three schools in a region in England that has suffered economic deprivation and low educational attainment. It sought to uncover how factors such as schools, teachers, friends and families, and the provision of IAG, impact on pupils' ideas about careers and higher study. Several investigations have set out how this provision and subsequent choice of progression to higher education (HE) is mediated through a number of cultural, social, economic and institutional influences. This research followed a mixedmethods approach to data collection, incorporating both quantitative and qualitative data collection tools that provided elements of positivist and interpretivist paradigms. The results reveal a complex landscape, characterised by a limited understanding of progression to $\mathrm{HE}$ and a lack of clarity about options, but nevertheless there are aspirations towards further study. The research has implications for IAG provision and has potential impact with respect to the need for a more consistent approach.
\end{abstract}

Key Words: university, IAG, progression, careers, qualifications

Acknowledgements: The author wishes to acknowledge the assistance of colleagues at the University of Wolverhampton Outreach Team in the collection of data for this research; including Sukhdeep Duhra, lan Hart and Professor Nazira Karodia.

\section{Literature}

\section{Social factors influencing choice and decision-making}

Support for pupils in making choices about their futures has been defined as "careers education, information, advice and guidance (CE/IAG); intended to encourage young people to make suitable educational and career decisions" (Nicoletti and Berthoud 2010, 72). There has been increasing interest in the provision of information, advice and guidance (IAG) with respect to progressing to $\mathrm{HE}$ (Diamond et al. 2014). A range of reports from diverse organisations such as the Higher Education Funding Council for England (HEFCE), the National Student Forum (NSF), a House of Commons Committee, and the Confederation of British Industry ( $\mathrm{CBI}$ ) have in the last ten years produced reports that have included discussions about available IAG for prospective students (Oakleigh Consulting and Staffordshire University 2010). How IAG is accessed and consumed is determined by a 
diverse range of factors that include social and environmental issues that can be complex (Moogan and Baron 2003). These include peer relationships, behavioural traits and environmental factors (e.g. home); mediated through emotional as well as cognitive and behavioural approaches to knowledge acquisition and usage, augmented by social networks.

Social factors impact on the decision-making process and are considered especially important when choosing progression routes (Diamond et al 2014, 4-5). In terms of school choice, working class families feel they do not have the relevant skills to make informed choices (Reay et al 1998). Students with more qualifications relied on parents for advice, whilst the influence of careers officers is lowest (Moogan and Baron 2003). Prospective HE students are often inexperienced "with neither well-defined choice criteria nor any knowledge of various brands" (Moogan and Baron 2003, 273). Providers of information about HE need to engage with school students and those who influence their thought processes. Decisions made about careers, courses and HE destinations do not always follow a completely rational process, sometimes depending upon emotional responses and what feels right (Diamond et al 2014, 5-6); part of an intuitive response.

Choices will differ depending on life experience, which is "nuanced and specific to individual circumstances". A more reflexive approach to providing IAG and the encouragement of students to reflect on their preferences is recommended (Diamond et al 2014, 52-54). This may be especially important to first generation students and their families; Reay notes that choice for more affluent families is an embedded and strategic process, part of their social reproduction, for the working classes choice is based on necessity (Reay and Ball, 1998). In families with less social and cultural capital to make informed choices children have greater influence, and choice is left more to the child (Diamond et al 2014). This means that any IAG offered by teachers, careers officers, schools and universities may be critical. The process of choice is also gendered, with girls finding it more difficult to decide what they feel is right for them (Moogan and Baron 2003). To add to the complexity; age, special educational needs, educational attainment, gender and ethnicity influence levels of IAG provision (Nicoletti and Berthoud, 2010). Paradoxically, Kettley and Whithead (2012) observe a convergence in students' choice making, suggesting that intention to participate in HE is a judgement made independent of class or gender that illustrates a homogeneous response. Alternatively, Ball et al's study of ethnic choosing suggested patterns in decisions to attend university by ethnicity and identity, but that differences must also take account of social class (2002). Furthermore, "capital and habitus play central roles in shaping aspiration towards HE and in gaining access to HE institutions" (Demack et al 2012, no page number).

Complexities of choice are combined with progression issues faced by disadvantaged and under-represented groups, this has the potential to create significant barriers to students, often through the intersectionality of gender, ethnicity, socioeconomic status and wider social, cultural and economic factors (Bowes et al 2015). Additional factors involved with successful decision-making include family and peer support, education networks, positive attitudes towards education, and relevant and timely IAG. Reducing barriers include tailoring support, raising awareness, empowering young people and "supporting young 
people to access and make effective use of information... to build a relevant choice architecture" regarding education and career preferences (Bowes et al 2015, 15).

\section{Parental influence}

Parents form an integral part of the decision-making process; in terms of career choice, there is quantitative evidence to suggest that parents have a greater influence than teachers (Kniveton, 2004). An increase in weekly household income is directly related to an increase in the probability of making a positive decision to attend university (Oliveira and Zanchi 2004). However, this is not without its complications, it has been suggested that parents of lower socio-economic status (SES) are less well informed and will find it more difficult to obtain and determine what is accurate and reliable information (Haynes et al 2013 , 461). Families in low SES locations take on a greater influence in pupil choices as young people become more reliant on their parents (Smyth and Banks 2012); but for post16 education options, parents can also be a weak link (Foskett 2008). Their influence may be shaped by several factors including social and cultural capital and being involved in support networks; furthermore "disadvantaged students and their families tend to be more dependent on their schools for access to the resources relevant for post-secondary educational attainment" (Smyth and Banks 2012, 272). However, some young people observed that their parents did not understand the choices, when it came to choosing study routes available in school (Haynes, et al 2013). In terms of making decisions to "elite" universities, there is evidence to suggest that the parents of working-class students are not at all apathetic, on the contrary many such parents are quite supportive, nevertheless they do lack practical experience and skills in terms of the application process (Kettley and Whitehead 2012).

For families who have limited interaction with $\mathrm{HE}$, through interventions there is potential to challenge entrenched perceptions that a university education is not for them (Bowes et al. 2015). Smyth and Banks (2012) compared the different forms of social reproduction in a school serving privileged families to a school that attracts pupils from a less advantaged working-class area. Their conclusions are a complex synthesis of choice-making, family and peer support and school habitus, requiring a need to: "integrate the rational and social reproduction perspectives. Young people make rational decisions about attending higher education, but rationality is 'bounded' by their individual, familial and institutional habituses" $(2012,279)$.

A statistical analysis of pupils acknowledges parental attitudes that can be channelled to children via strong social relationships; playing an important role in determining the ways in which aspirations, expectations and achievements are played out (Khattab 2015). Furthermore, the most important factor of applying to university are parents (2015). If parents do not feel empowered to support their children, then their offspring will have low expectations and be at a significant disadvantage. It has been suggested parental relationships with their offspring is closely related to the social and economic background of the family (Hill and Craft 2003); emphasising a need for the provision of effective IAG for those from less affluent homes. Unfortunately, "there is no clear evidence that IAG is especially effective for those in most need of it" (Nicoletti and Berthoud 2010, 9). 


\section{Peer relationships}

Friends' and peers' influences on students' HE choices has been highlighted; often formed around a hierarchy based on ability and social networks, influenced by different cultural capital. Decisions on institutions and courses have been developed through peer relationships and friendship groups (Brooks 2004). However, "grapevine knowledge" is uneven, time and resources dedicated is also dependent upon the disposition to commit to information and knowledge gathering and the utilisation of professional support structures (Ball et al 2002, 353). The process of choice is related to class and the concept of what Ball calls contingent and embedded choosers, the former possessing a weak sense of their future, "part of an incomplete or incoherent narrative... first-time choosers with no family tradition of higher education" (Ball 2002, 337). Some young people have little knowledge or understanding of employing realistic plans for their future. It has been suggested that good quality and impartial school-based IAG has consistently proved to be elusive (Haynes, et al 2013).

\section{School factors}

The barriers that students face also bring into sharp focus the notion of institutional habitus. It has been observed that state schools are less ambitious in the application process to elite universities, compared to independent schools, who are much more proactive. Some schools offer relatively little in terms of education and career progression. In research on pupil progression "the majority of respondents suggested that the schools did not offer them a realistic appraisal of what opportunities were open to them" (Bowes et al 2015, 77), leaving many young people to rely on their own research. There are contrasting institutional approaches creating gaps in expectations between the higher aspirations of students compared to teachers and counsellors (Smyth and Banks 2012, 277 and 274). Schools play an integral part of the decision-making process, whether that be curriculum options, careers or further study. Whilst all schools provide information, advice and guidance, it has been suggested that schools serving low socio-economic status (SES) areas provide a very different service geared to courses perceived as lower status, reflecting and reinforcing the academic/vocational divide. Limited social and cultural capital (with respect to educational choices) means that children and families from low SES backgrounds rely more strongly on school-based IAG (Foskett et al 2008). It makes the understanding of choice and aspirations even more critical and the institutional role significant. Byrom's study of students' aspirations draws on Bourdieu when observing the "school effect" on students determining their strategies and choices for HE, as well as their "habitus" and "the hard work of their teachers" $(2009,221)$. However, students' choices are not simply framed by socio-economic background; but are influenced by totality of experience (Kettley and Whitehead 2012).

A corollary is that the role of guidance professionals and the knowledge of teachers is important. They can influence thinking and play a critical role in supporting young people from families with little or no background or tradition of post-16 education "the agency of individual teachers is an important factor in creating the right conditions for students", 
holding "unique positions of influence" (Oliver and Kettley 2010, 750). However, low expectations of students from some staff can lead to a channelling into courses seen as lower status (Haynes 2013) reinforcing stereotypes and social reproduction. Greater encouragement from teachers, advisors and family networks, together with a consistent institutional culture, will assist in the promotion of higher education (Kettley and Whitehead 2012). It has been suggested that teacher habitus requires attention; "teachers' political and ethical dispositions as well as their social capital are potential factors in shaping students' decision-making about HE" (Oliver and Kettley 2010, 737). At schools and colleges that had a low rate of sending their students to elite universities, teachers believed family links contributed to students' near-sighted and narrow-mindedness when considering university. The has been a call for widening participation professionals to focus more on state schools and engage their teachers, who play important roles in laying foundations that will shape the destinations of their students (Oliver and Kettley, 2010).

Compounding these issues is the reliability of IAG, with some pupils receiving insufficient information regarding the range of opportunities (Haynes et al 2013). Certain school factors significantly influence pupils' decision-making, including whether a school has a sixth form, the socio-economic context of the school, school leadership and culture, and school organisation (Foskett 2008). Such institutional habitus is also reflected in Smyth and Banks' work (2012). Different schools manage the IAG process in different ways. Schools in high SES areas tend to have more sixth forms than those in low SES areas and seek to maintain status through a strong academic ethos and progression to HE. "SES is key to underpinning influence... it is strongly influential in shaping the dominant ethos and explicit aims and aspirations of the school" (Foskett 2008, 60). There is also self-fulfilling prophecy at work; young people that get the most out of advice and guidance were the same as those who had the greatest chance of staying in full-time education anyway (Nicoletti and Berthoud 2010); suggesting an important role for the way IAG informs pupils and families that are not familiar with prospects. A call for further research suggests looking at ways schools can be encouraged to provide better IAG, and an investigation into the practice of IAG provided by subject tutors (Oakleigh Consulting and Staffordshire University 2010).

\section{The role of universities}

Several reports have also published conclusions about the role of the higher education institution (HEI) in providing good quality information, advice and guidance to help the decision-making process; including information regarding employment prospects, bursaries, course content and non-academic aspects of student life. In addition, further clarification in the use of technical language relating to $\mathrm{HE}$ is needed as this can be a barrier to understanding (Oakleigh Consulting and Staffordshire University 2010), as well as proactively developing partnerships and links with universities that include "Immersive experiences of university" (Thornton et al 2014, 148).

\section{Some general conclusions}


Thornton et al's (2014) study concludes that schools and colleges play an important role in encouraging their students to apply to HE and observed high levels of commitment from such institutions. They added that best practice for schools and colleges should include: a whole institution culture of raising aspirations, universal and targeted approaches, specialist and knowledgeable staff with respect to careers and access to $\mathrm{HE}$, early interventions from Key Stage 3 (Years 7-9), and advice and support on applications. Furthermore, for disadvantaged groups, others suggest a set of wide-ranging conclusions relating to raising aspiration and addressing barriers and benchmarks for engaging with schools. For example, a series of age and stage interventions including early engagement with young people, effective IAG, informing parents of pathways, careers advice about the labour market and formal advice (Bowes et al, 2015). However, Bowes et al remind us of what others have reiterated in different ways, that is influential factors on decision-making on progression to $\mathrm{HE}$ are mediated through a complex composite of social, cultural, economic, personal, peer group, family and institutional habitus; it is difficult to identify one significant factor (Bowes et al, 2015).

\section{The regional context}

The research took place in three schools near to Wolverhampton in the United Kingdom. Wolverhampton is a city in the English Midlands. In recent times the decline of traditional engineering industries has resulted in higher levels of unemployment and deprivation, and "the region remained less well positioned to play a part [in the knowledge economy] given weak traditions in "knowledge creation'"; this reflects a region that has relied heavily on manufacturing and less so on education (Haynes 2008, 17). The region (known colloquially as the Black Country, a historical reference to its reliance on a heavy industry economy) has some of the highest levels of deprivation in England, with relatively low levels of training and skills (Department for Communities and Local Government, 2015). Lower education attainment is highlighted by several reports: to reach the national average of $35.7 \%$ qualified to degree requires a further 89,942 people in the region to be educated to this level (Black Country Consortium, 2016, 9). Furthermore, nearby (rural) regions have similar challenges in terms of unemployment, education and training (The Marches Local Enterprise Partnership 2016). The Black Country region has a population of nearly 1.2 million; although the proportion of residents with no qualifications is reducing (from just over $20 \%$ in 2004 to $16.7 \%$ in 2014) it is significantly above the England average of $8.6 \%$ (Black Country Consortium 2016).

\section{Justification for the research}

It was against this local backdrop that the research was initiated. The aim was to identify how younger generations in the area are considering their futures in terms of qualifications, training, and employment; and what advice and support they were getting. Identifying factors that impact on GCSE achievement and progression to higher learning will be important to the areas of Shropshire, Staffordshire and the Black Country, if they are to fulfil 
social and economic ambitions. Filling skills gaps and enabling businesses to recruit sufficient employees with the required skills to contribute successfully to their operations are critical to plans for economic growth and sustainability. The research looked to inform education strategies aimed at progression to $\mathrm{HE}$, within a context of high skills gaps and the need to attract and retain enterprises which depend upon a highly skilled workforce. It looked to identify whether there were differences or similarities to our understanding of progression, and if local conditions correlated with current literature.

The research project investigated the following:

1. How has Information, Advice and Guidance (IAG) in school played a role in promoting progression beyond GCSE?

2. What has been the contribution of the home?

\section{Methodology}

"Gaps" data from the Higher Education Funding Council for England (HEFCE http://www.hefce.ac.uk/analysis/yp/gaps/) identified participation of 18 and 19-year olds in higher education in England. The data allows researchers to investigate participation by census ward (a localised geographic area) to look at expected participation rates and participation gaps (the difference from the expected young participation level). Schools were identified in the areas of Wolverhampton, Staffordshire and Shropshire that were not achieving especially well in terms of G.C.S.E. exam results, but nevertheless had a good record in terms of their pupils progressing to HE. The schools (No $=8$ ) who fell into this category were approached to take part. Eventually three schools agreed to participate in the research.

The proportion of students in the Black Country who achieved 5+ A*-C GCSEs rose to 50.5\% in 2014/15. This compares to the national (English) figure of 53.8\% (Black Country Consortium 2016, 9). Of the 81 secondary schools in the region, 48 performed below the national average level. Over the period 2005/06 to 2014/15, the Black Country's performance on GCSE qualifications has risen by 14.7 percentage points, from $35.8 \%$ to $50.5 \%$, compared to an average of 8 percentage points increase nationally.

\section{The School context.}

Three schools relatively close to the city of Wolverhampton participated in the research. Wolverhampton represented an appropriate location for the focus of the research as it lies to the northern end of the Black Country region, but also has wider geographic and economic connections with the nearby rural counties of Staffordshire and Shropshire, the latter falling within the area of the Marches Local Enterprise Partnership.

The three schools sampled from the Wolverhampton post code areas were anonymised, but described as follows: 
River Valley School. This school is a High School with a Sixth Form, situated in a semi-rural location and serving a local village near Wolverhampton. It is a secondary comprehensive, mixed gender, serving 11-18 year olds. It gained Academy status in 2015 and, at the time of writing, was still to be to be inspected by Ofsted (Office for Standards in Education) following this move. The last Ofsted report in 2013 stated the school required improvement in terms of its overall effectiveness; Ofsted observed it was an "average size" school consisting of pupils mostly from White, British backgrounds. The proportion of pupils supported by the pupil premium (a government initiative designed to provide additional funding for schools to help disadvantaged pupils achieve) is below the national average. River Valley state that it maintains high academic standards and compares favourably with local and national averages.

Wulfruna. This school is also a co-educational comprehensive, serving a town in Staffordshire approximately forty minutes' drive from Wolverhampton City centre. It has 1,430 pupils on the roll. The school's Ofsted visit (2014), resulted in a move from "satisfactory" to "good" on its overall effectiveness. Ofsted noted that the school is "much larger" than most secondary schools and that most pupils are from White British backgrounds. The number of pupils supported by the pupil premium is below average. Wulfruna states that it promotes a caring, safe and positive environment within school, encouraging a positive self-esteem and effectively tackles bullying and harassment.

Ridgeview. This is a "community school" in a predominantly working-class suburb of Wolverhampton, approximately ten minutes' drive from the City Centre. An Ofsted inspection in 2015 concluded it was a "good" school across all areas of school life. It is a "smaller than average" sized school with a very large majority of pupils from minority ethnic backgrounds. The proportion of children attracting the pupil premium is above the national average. Ofsted also noted 'Students' spiritual, moral, social and cultural development is good. The successful promotion of mutual respect and the celebration of diversity are at the core of the school's work". It has a Sixth Form and states that 90\% of its 2012 Year 13 students went on to study at University.

\section{Research design}

The research took a pragmatic mixed-methods approach to data collection, incorporating both quantitative and qualitative data collection tools that provided elements of positivist and interpretivist paradigms. The aim was to arrive at a more nuanced approach to data collection (Cohen et al 2011). A questionnaire was deployed across three schools (in Years $9,11,12,13)$, presenting a snapshot concerning pupils' thoughts; the survey utilised tick boxes, multi-choice responses and Likert scales. Within this format, space was designed to allow open-ended free-text responses that added a qualitative element to the data. Questions covered a range of themes including: attitudes to school and study, thoughts on further education and training, career and university aspirations, and the provision of advice and guidance. In addition to this a focus group interview was conducted with students from one school's Sixth Form (Years 12-13), the group explored the perceptions of sixth-form 
students with respect to going on to university. Following the collection of quantitative and qualitative data, the results were triangulated and coded to represent a series of emerging themes and conclusions.

\section{Participants}

The total sample size for all schools amounted to 1160 students from Years 9-13. The majority of responses (65\%) were taken from Years 9 and 11 in roughly equal measures, with 18\% coming from Year 12 and 17\% from Year 11.

\begin{tabular}{|l|l|l|}
\hline \multicolumn{3}{|l|}{ Questionnaire Survey* } \\
\hline Year & Approximate Age & Responses \\
\hline 9 & 14 & $394(34 \%)$ \\
\hline 11 & 16 & $360(31 \%)$ \\
\hline 12 & 17 & $209(18 \%)$ \\
\hline 13 & 18 & $197(17 \%)$ \\
\hline \multicolumn{2}{|l|}{ Total = } & 1,160 \\
\hline
\end{tabular}

( ${ }^{*}$ The data that support the findings of this study are available on request from the corresponding author. The data are not publicly available due to restrictions containing information that could compromise the privacy of research participants).

Results (90\% response) suggest that parent/carer occupations represented a diverse range of employment. As a general indicator, responses considered a professional occupation were added to those replies that clearly indicated a managerial role, consultancy, and directorship positions. These combined categories suggest that $44 \%$ of occupations could be described as a "professional" role. In terms of qualifications, $36 \%$ of pupils indicated that one of their parents had an undergraduate or postgraduate degree, however $29 \%$ of respondents indicated that they were unsure of their parents' qualifications.

\section{Focus groups}

The focus groups followed a semi-structured interview design that enabled researchers to discuss key issues uncovered in the questionnaire and in the literature, whilst providing a flexibility that encouraged students to discuss and explore themes that they wished to raise (Denscombe, 2010). Students were given the opportunity to raise any other issues that were pertinent to their experience but not covered throughout the rest of the interview. The students' permission was sought for the interview to be digitally recorded. The interview was then transcribed and coded. The aim was to invite honest, personal comments from respondents, the content of which might include rich information that would not otherwise be collected (Cohen et al, 2011). Emerging themes were sought, and connections made between them; the results were compared to their relationship with extant literature and the questionnaire data. Throughout all the approaches to data collection, ethical considerations were of the utmost importance in working with young people under the age to give informed consent and parents' permissions were sought. Students responses were 
anonymised throughout the survey in terms of both quantitative and qualitative responses. The aim was to achieve a level of saturation (where no new insights are produced) and enable a confident discussion of the data and how it relates to the theory and practice.

A process of thematic analysis was applied, known for its flexibility as a research tool, the aim was to identify, analyse and report patterns or themes within the data. The analysis followed an inductive approach that allowed themes to emerge, not wedded to an existing theoretical framework. Through a contextualist approach, the analysis sought to acknowledge individual meanings but also consider the more expansive social context that the students, schools and families operated within and that influenced meaning-making at an individual level. Analysis developed from the shuttling between data sets whilst coding the data, from which the themes developed. Through a constructionist perspective, the intention was to develop themes that helped theorise socio-cultural (Braun and Clarke, 2006) aspects around choices of progression.

A mixed-method methodological triangulation, combining quantitative and qualitative tools, was employed to establish greater validity and uncover emergent and convergent themes. Such an approach has been valued by researchers and can combine normative and interpretive techniques (Cohen et al, 2011).

\section{Findings and Analysis}

\section{Diverse aspirations}

Pupils were invited to respond to questions relating to aspirations with respect to work, training and education. When asked what occupation they saw themselves in, in ten years' time, a wide range of responses were recorded ranging from "Barrister" to "Tattoo Artist". A significant number of students were vague, suggesting "something to do with...". This is also exemplified by several contradictory statements, for example "accountant or performer", "investment banker or engineer", "actor or car mechanic," "karate teacher or therapist". That said, many of the occupations were high status, requiring higher level qualifications. To quantify such high diversity of responses, different occupations were classified into careers that would probably require a degree level qualification. This then suggested that around two-thirds of occupations that pupils chose would require degree level study, with $15 \%$ of pupils being "unsure" about their occupation.

Asking about what training they felt they would need for their chosen occupation revealed paradoxical results to the previous question, with $46 \%$ of pupils stating they would need a degree level qualification. This may reveal a difference in levels of expectation compared to the reality in the current jobs market. Only $3 \%$ felt they needed a vocational qualification and $37 \%$ either not indicating what they thought they needed or were "unsure". This difference may be down to any number of reasons, including lack of accurate advice, overconfidence, lack of information on which to draw realistic conclusions, or lack of understanding of the jobs market. Pupils may not realise increasing pressures and competition that reflects a growing credentialist environment. Whatever the explanation, it 
suggests that pupils would benefit from more accurate and realistic advice on what qualifications are required to get into certain professions, however, more research would be helpful.

\section{Making choices regarding their education after school - the influence of Parents, Guardians and Teachers}

A series of questions were asked that related to pupils' choices on leaving school. An interesting comparison can be made between progression to an apprenticeship or a degree. For example, only $14 \%$ of students felt they would take up an apprenticeship, whilst $41 \%$ said they would not. A significant proportion (36\%) remained unsure, giving an answer of "maybe". However, 64\% indicated their intent to go to university (even though only $45 \%$ felt they needed a degree). Only $8 \%$ said they are not thinking about going to university. The results suggest that the advantages of modern apprenticeships are not apparent to school pupils and their status is problematic. More work is required if pupils are to consider this qualification as a realistic alternative, especially as $57 \%$ of Year 9 students said they were going to university, increasing to $74 \%$ of Year $13 \mathrm{~s}$. Clearly, university study remains the more attractive option, despite increasing fees and student debt. That said, a significant proportion of students were undecided (26\%) and would benefit from additional advice and guidance.

Pupils were then asked to consider their own motivations and the influences of parents, guardians and teachers. Pupils re-affirmed their intent regarding university, with $65 \%$ of pupils across Years 9-13 saying that they "want" to go to university. Comparisons between parents and teachers revealed an interesting paradox; $60 \%$ of pupils agreed that their parents wanted them to go to university, with only 6\% saying "No" and $31 \%$ indicating "Maybe". This compares to $36 \%$ of pupils saying teachers wanted them to go to university; $54 \%$ replied "Maybe", with 7\% saying "No" their teachers did not want them to go to university. These responses represent one of the most intriguing aspects of the whole survey and there are several possible explanations. For example, either teachers feel they do not have the time, knowledge or expertise to effectively support pupil aspirations and progression (even though they could act as role models, having attended university themselves), teachers are unsure of pupils' ability or potential to progress to university, or pupils are unclear about their teachers' views on going to university. Whilst teachers' expectations increase significantly by Year 13, in line with parental indicators, further investigation is required and possibly more could be done to encourage schools and teachers to support pupils in realising their aspirations.

Pupils were then asked to consider IAG with respect to progressing to university. When asked whether their school had given them information on this issue nearly $50 \%$ of all students disagreed that this was the case, whilst $29 \%$ agreed. By year $13,57 \%$ agreed that the school had provided information. However, this still leaves a significant minority that either disagreed or were insure. When asked whether teachers encouraged them to think about university only $40 \%$ appeared to agree with this statement, whilst $31 \%$ disagreed. $\mathrm{A}$ 
significant minority (28\%) were unsure. However, by Year $1382 \%$ either agreed or strongly agreed that their teachers encouraged them to think about university, suggesting that by around 17-18 years of age a much greater emphasis had been placed on encouragement and progression. This is reflected in that for Year $13,76 \%$ of pupils stated that they had careers advice in school, with respect to university and other options. However, across the total sample of Years 9-13 (No $=1160) 54 \%$ either disagreed, strongly disagreed or were unsure whether they had this kind of advice from Careers. By Year $1352 \%$ of pupils indicated that university staff had visited their school. Given that a much larger proportion of Year 13s had aspirations to go to university (74\%), it suggests that more visits are recommended, or that visits are taking place but either many students did not realise this was the case or are not befitting from this experience. Universities can play a significant part in the provision of accurate IAG and a further exploration of these outreach activities is needed.

\section{Peer networks and knowledge about progression options}

Pupils did indicate that they had talked to their friends about going to university. Across all years there was a much more positive response. $60 \%$ either agreed or strongly agreed that they had been talking to each other about university. By Year 13, this had risen to $93 \%$. A similar question relating to discussions with their class mates elicited comparable findings, with $54 \%$ either agreeing or strongly agreeing, rising to $88 \%$ by Year 13 . A quarter of pupils indicated that if they were to go to university at all, they intended to go to an institution in the English Midlands. However, results from Year 13 indicated that only 35\% had started preparing for their application, with 58\% not completing the question. Given the much more positive discussions shown by Year 13s when talking about university, there appears to be some ambiguity compared to the lower responses, with respect to preparation and application; further investigation is needed.

Pupils were given the opportunity to provide free-text comments, relating to university and advice and guidance. Fifty pupils responded with a wide range of comments, but mostly categorised as relating to further advice and guidance and requests for greater information. Other comments related to UCAS (Universities and Colleges Admissions Service), debt and careers advice. The following replies reveal a range of issues and very different levels of knowledge and understanding:

"I know literally nothing about university"

"I don't know the difference between University and College"

"I would like more advice about university and subjects to study as I am unsure and not getting any support"

"I have learnt nothing about anything to do with university, and I think we should". 
To provide further contextualised data, four focus groups were conducted with Year 12 and Year 13 pupils in one school (Ridgeview). Fourteen pupils (7 in each year) expressed their views on HE progression. The pupils were selected from those sixth forms in a socially and economically disadvantaged Ward, whose pupils progressed on to HE in larger numbers than would be predicted by their school's overall GCSE performance. The discussions were recorded, analysed, transcribed and then coded; a thematic analysis was applied.

With regards to $\mathrm{HE}$, all students appeared to be aware of some of the demands of studying at university. Students noted the focus on independent study. Teachers and older siblings provided key sources of information and cultural capital with respect to the understanding of university demands. Such an awareness is important; being able to adjust to a university environment is a key factor in early attrition rates, retention, and degree outcomes. However, some students who had just started their Sixth Form indicated that they did not feel ready to move to a university teaching and learning style.

Teachers say that you will have to put more effort than for your A-levels and you'll have less time to revise (Year 13).

[At University] You will not have much help, you will have to do it by yourself (Year 13)

Obviously, you have the same teachers for 6 years and you have support from them. And suddenly changing atmosphere is very scary (Year 12).

It was interesting to note that the majority of students would be "first generation" attending university if they eventually go, although for most going to university had always been in their plans.

I think I have never assumed that I was not going to university. It's the next step, you don't really question it. (Year 12)

I think it's just normal, everybody, you go to school and you just know that you will go to uni. [...] You just know that you go to primary school, secondary school and then university. (Year 13)

A minority had thought about an apprenticeship, but only one considered it seriously; correlating with the data from the questionnaires. Generally, it was felt that apprenticeships limited their professional development and range of potential jobs to one specific industry. It seemed that students felt a degree would provide them with more options in the world of work; something that apprenticeships providers need to consider.

With apprenticeship you have to know what industry you definitely want to go into and that's what apprenticeship is for, you actually are going into that. But I don't really have one industry I want to work and I think uni gives you a degree to have a wider range of jobs you can go into later (Year 12). 
For most respondents, the family environment played a significant role in encouraging students to consider university study, reflecting the findings of the quantitative survey. Some pupils commented that their parents' message was that university would open more opportunities and better job prospects, a couple of students even felt pressured into going to university. There appeared to be a clear aspiration to become socially mobile and this seemed to be behind some pupils' decisions.

I have seen how my parents have struggled, not having been to university. I feel like when you have that qualification... you are more likely to get a job. And my parents always said to me: if you have education, no one can take it from you. So, seeing them like that made me want to go to university (year 12)

[My dad said to me:] That's your choice, if you want to go the hard way, you will have to work much harder to make money. But if you go to university you will work hard and people will respect you, you will have a better qualification (Year 13).

For some pupils, older siblings who had already graduated or studying at university provided some positive examples to relate to, boosting their confidence in being able to cope in such an environment.

Having all the cousins as well that have been to University has made me thought that that's a good option, your career options are more varied (Year 12).

By the time they entered Year 12/13, pupils felt school and teachers were supportive of their choice to progress to $\mathrm{HE}$ and some teachers were strongly encouraging. No-one felt they had been discouraged.

Our teachers, towards me and her [pointing to another participants and our friends, they encourage us strongly to go to university (Year 12).

They [our teachers] make it like it's not hard. It's the next step but it's not as hard as... it's within your capabilities, so they encourage us to go (Year 12).

All seemed aware of the financial implications, however none of them seemed worried about ending up in debt (contrary to concerns expressed by some teachers).

You do have to pay and we'll get a debt after but it's fine, you can handle it, it's an inconvenience rather than something that would discourage you (Year 12)

I am not really worried because my brother is now at university and I see him and he's not really struggling, so I know that I have a budget and I'm not stupid with money (Year 12)

Yes [I feel comfortable with this debt] because what you get out of it is a degree, a foundation to get a job and get a salary that is good enough to pay back (Year 13)

The focus groups consolidated several key points in the research and the literature, that family environment and parental attitudes are key and that many are aspirational in terms 
of HE progression. The school environment is also important to help inform the decisionmaking process and progression requirements, especially in the absence of family knowledge of HE. However, it is interesting to note that overall, students do not appear to be put off by fees and student debt and accepted it as part of the deal. There appeared to be a divergence from teachers' views that indicate a more negative viewpoint. This needs to be explored further.

\section{Conclusion}

There are limitations to this research, in that there was not a strong emerging pattern or overriding trend. Rather, the findings were subtle and yet detectable and have implications for IAG for young people and their families. They reinforce some of the literature in that young people appear to have a limited understanding or realistic plans for their future and high quality impartial advice remains elusive (Haynes et al 2013). Such advice needs to be within a framework of support offering discussions that appraise opportunities (Bowes et al. 2015) and set out clear directions. Whilst there were some clear expressions and intent suggested in the data, there was also a sense of ambiguity and uncertainty. Career aspirations reflected a wide range of contradictory ambitions, even at individual level. Furthermore, although many occupations pupils sought were relatively high status, there seemed a lack of clarity about the qualifications that provided a route to those professions. However, students were much clearer about not taking an apprenticeship, feeling that this option restricted choice of career direction.

There was an interesting comparison to be made between teachers and family, in terms of supporting progression. Whilst teachers could offer advice on what to expect when studying at university, many pupils felt unsure whether teachers were encouraging them to go. However, in general the family environment appeared to be much more positive about university progression, both in the qualitative and quantitative data. Across the sample, the difference between teacher and parental support became apparent and further research to explore the subtleties of the two approaches to pupils' aspirations would be welcomed. Teacher habitus and dispositions informing students' decision-making is a key element that needs to be addressed (Oliver \& Kettley, 2010), the findings in this research align with this idea, furthermore it matches Smyth and Banks' (2012) observations concerning a gap in expectations. One implication is that institutional habitus and culture also needs to be aligned to play an important role (Thornton et al. 2014).

Whatever their choice, the data from pupils suggested the need for more or clearer IAG. Many indicated that their schools had not provided enough information with respect to university progression. Whilst a much more positive picture emerged by Year 13, overall many seemed unsure about the advice their school could offer on university or career progression. This was reinforced by the free text responses where pupils responded with a general lack of understanding and clarity about university options. This also correlates with Moogan and Baron's analysis (2003) that students are afflicted by poor choice and knowledge of $\mathrm{HE}$, reflecting the notion of the "contingent chooser" (Ball, 2006). Whilst a 
persistent call is to raise aspirations and empower families through choice, it is difficult to see how this can be realised if they do not know what it is they are choosing or aspiring to, exactly. To extend Bowes' architectural metaphor (2015), students and their families need to be scaffolded more towards their goals. Kniveton (2004) concluded that parents have a greater influence than teachers with regards to career choice and evidence of the importance of parental support is replicated in this research. Furthermore, there is a suggestion that, unlike teachers, pupils do not appear as put off by fees. Although significant emphasis is placed on IAG transmitted by schools and teachers, the signal received appears to be some-what scrambled for pupils and their families. A three-way compact that includes teachers, universities, and parents and guardians much more, could lead to better informed and productive outcomes.

\section{References}

Black Country Consortium Ltd. 2016. The Black Country Annual Economic Review. The Black Country: a place to live work invest. Economic Intelligence Unit.

Braun, V. and Clarke, V. (2006). Using thematic analysis in psychology. Qualitative Research in Psychology 3 (2): 77-101.

Department for Communities and Local Government. 2015. The English Indices of Deprivation. Crown Copyright.

The Marches Local Enterprise Partnership. 2016. European Structural and Investment Funds Strategy $2014-2020$.

Oakleigh Consulting and Staffordshire University. 2010. Understanding the information needs of users of public information about higher education. Report to HEFCE. Manchester.

Ball, S.J. 2006. Education Policy and Social Class. The selected works of Stephen J. Ball. Routledge. Abingdon.

Ball, S.J., Reay, D. and David, M. 2002. "'Ethnic Choosing': minority ethnic students, social class and higher education choice". Race Ethnicity and Education 5 (4): 333-357. 
Bowes, L. et al. 2015. Understanding progression into higher education for disadvantaged and under-represented groups. A report by CFE Research for the Department for Business, Innovation and Skills (BIS).

Brooks, R. 2004. "'My mum would be as pleased as punch if I actually went, but my dad seems a bit more particular about it': paternal involvement in young people's higher education choices". British Educational Research Journal 30 (4): 495-514.

Byrom, T. 2009. "'I don't want to go to a crummy little university': social class, higher education choice and the paradox of widening participation". Improving School 12 (3): 209224.

Cohen, L. Manion, L. and Morrison, K. 2011. Research Methods in Education. Routledge. $7^{\text {th }}$ Edition.

Demack, S., Stevens, A., and McGaig, C. 2012. 'Dreams' \& 'Realities' in University Access:

Mapping social differences in Higher Education aspirations and participation in England. Final Report. Sheffield Hallam University. Centre for Education and Inclusion Research.

Diamond, A. Roberts, J. Vorley, T. Birkin, G. Evans, J. Sheen, J. Nathwani, J. 2014. UK Review of the provision of information about higher education: Advisory Study and Literature Review. CFE Research.

Foskett, N. Dyke, M. and Maringe, F. 2008. "The influence of the school in the decision to participate in learning post-16". British Educational Research Journal (1): 37-61.

Haynes, M. 2008. The Evolution of the Economy of the West Midlands 1700-2007. University Wolverhampton Business School.

Haynes, G. McCrone, T. and Wade, P. 2013. "Young people's decision-making: the importance of high quality school-based careers education, information, advice and guidance". Research Papers in Education 28 (4): 459-482.

Higher Education Funding Council for England. 2018. Gaps in young participation in higher education. Accessed 30 January 2018. http://www.hefce.ac.uk/analysis/yp/gaps/ 
Higher Education Funding Council for England. 2013. Trends in young participation in higher education. October 2013/28.

Hill, N. E. \& Craft, S. A. 2003. "Parent-school involvement and school performance: Mediated pathways among socioeconomically comparable African American and EuroAmerican families". Journal of Educational Psychology, 95 (1): 74-83.

Kettley, N.C. and Whithead, J.M. 2012. "Remapping the "landscape of choice": patterns of social class convergence in the psycho-social factors shaping the higher education choice process". Educational Review 64: 493-510.

Khattab, N. 2015. "Students' aspirations, expectations and school achievement: what really matters?" British Educational Research Journal 41, (5): 731-748

Kniveton, B.H. 2004. "The Influences and Motivations on Which Students Base Their Choice of Career". Research in Education 72 (1): 47-57.

Moogan, Y.J. and Baron, S. 2003. "An Analysis of Student Characteristics within the Student Decision Making Process". Journal of Further and Higher Education 27 (3): 271-287.

Nicoletti, C. and Berthoud, R. 2010. The Role of Information, Advice and Guidance in Young People's Education and Employment Choices. Institute for Social and Economic Research. University of Essex. Report for the Department for Education. Research Report DFE-RR019.

Oliveira, T. and Zanchi, L. 2004. Participation in higher education in Britain: The effect of ability and parental income).

Oliver, C and Kettley, N. 2010. "Gatekeepers or facilitators: the influence of teacher habitus on students' applications to elite universities". British Journal of Sociology of Education 31 (6): 737-757.

Reay, D. and Ball, S. 1998. "Making their Minds Up': Family dynamics of school choice". British Educational Research Journal" 24 (4): 431-448. 
Smyth, E. and Banks, J. 2012. "'There was never really any question of anything else': young people's agency, institutional habitus and the transition to higher education". British Journal of Sociology of Education 32 (2): 263-281.

Thornton, A. et al 2014. School and College-level Strategies to Raise Aspirations of Highachieving Disadvantaged Pupils to Pursue Higher Education Investigation. Research Report. Department for Education. DFE-RR296 